\title{
Estudios sobre la lengua española hablada en el mundo hispánico en su variedad geográfica y social con materiales del PRESEEA
}

\author{
PRESENTACIÓN \\ Abelardo San Martín Núñez y Silvana Guerrero González \\ Universidad de Chile
}

El "Proyecto para el Estudio Sociolingüístico del Español de España y de América" (PRESEEA) constituye una iniciativa que se propone, de manera general, la conformación y el estudio de un corpus de lengua española hablada, representativo del mundo hispánico, en su variedad geográfica y social. Los gestores del PRESEEA reconocen al Proyecto de Estudio de la Norma Culta Hispánica (Lope Blanch 1986), como su principal y más cercano antecedente; no obstante, sus planteamientos teóricos y sus presupuestos de orden metodológico tienen su punto de partida en la sociolingüística urbana de base variacionista (Moreno Fernández 2009). De esta manera, se esperaba cumplir con una de las prioridades de la sociolingüística hispánica, esto es, describir la dinámica social de la lengua española mediante un proyecto coordinado que facilitara la comparación de sus distintas variedades (Silva-Corvalán 1994). El proyecto es el fruto del trabajo conjunto de investigadores comprometidos con una metodología común, a efecto de reunir un banco de materiales comparables que posibilite la aplicación de fines educativos y tecnológicos (Moreno Fernández 1997). En la actualidad, el PRESEEA agrupa a cerca de 40 equipos de investigación sociolingüística, que representan a comunidades de la mayor parte de los países de habla española (http://preseea.linguas.net/). 
En el marco del XVII Congreso de la Asociación de Lingüística y Filología de la América Latina (ALFAL), en João Pessoa, Paraíba (Brasil), en 2014, se presentaron avances en diferentes áreas y temas de investigación, relativos tanto a proyectos colectivos coordinados como a iniciativas individuales. En este contexto, se acordó estimular la aparición de publicaciones conjuntas, en formato de libros o de números monográficos de revistas, que incluyeran estudios sobre fenómenos sociolingüísticos de distintas variedades que emplearan los materiales del proyecto (http:// preseea.linguas.net/Metodologia.aspx). Con el propósito de favorecer y fomentar la investigación que emplee como base el corpus del PRESSEA, el Comité editorial del Boletín de Filología convocó a presentar colaboraciones para una sección monográfica titulada "Estudios sobre la lengua española hablada en el mundo hispánico en su variedad geográfica y social con materiales del PRESEEA". No obstante, tanto la calidad como la cantidad de trabajos seleccionados determinaron que dicho comité decidiera transformar la mencionada sección en un número monográfico independiente.

En este número monográfico se incluyen 10 artículos y tres notas que tratan sobre diferentes temas que han sido foco de atención por parte de los equipos del PRESEEA o de investigadores particulares que utilizan los materiales del proyecto en investigaciones descriptivas de alguna variedad del español o contrastivas entre las variedades de dicha lengua. Con su publicación esperamos contribuir, de manera específica, a uno de los principales objetivos que se propone el Proyecto, a saber, favorecer el conocimiento que se tiene del estado actual de la lengua española hablada en sus procesos de variación y cambio, en todos los niveles lingüísticos y en la mayor parte del mundo hispánico. Asimismo, se espera que la difusión de estos estudios redunde, entre otras consecuencias, en facilitar el conocimiento de los procesos de variación lingüística y el alcance de la variación sociolingüística de algunos fenómenos variables del mundo hispánico (Moreno Fernández 2009). En definitiva, con la publicación de este número monográfico esperamos aportar a la descripción de la diversidad sociolingüística de las comunidades de habla hispanohablantes, tal como se lo propusieran los profesores Francisco Moreno Fernández y Carmen Silva-Corvalán cuando comenzó a gestarse esta iniciativa.

Por lo que se refiere a los temas de investigación sociolingüística que se incluyen en este número monográfico, destaca la diversidad de intereses y propuestas. De esta manera, aunque los estudios de variación fonética son más numerosos, también los hay de variación sintáctica y discursiva.

Un grupo importante de trabajos de este número monográfico aborda la elisión de /d/ en posición intervocálica. Por una parte, Irania Malaver y Lorena Perdomo analizan este fenómeno en la comunidad de habla 
caraqueña. Por otra, Juan Andrés Villena y Juan Antonio Moya analizan, de manera comparativa, el cambio fonológico erosivo en la variación de /d/ intervocálica en las comunidades de habla de Granada y Málaga. Asimismo, Isabel Molina estudia la variación de la /d/ final de palabra en Madrid. Por último, la reflexión de conjunto acerca del estudio de la/d/ intervocálica en los corpus del PRESEEA queda a cargo de Irania Malaver y José Antonio Samper.

En otro orden, Yolanda Lastra y Pedro Martín Butragueño analizan la concordancia de haber existencial en la Ciudad de México, en tanto que Florentino Paredes trata la pluralización del mismo verbo en Madrid. El estudio de los marcadores del discurso también ha sido incluido en este número monográfico. De este modo, Juan Diego Aldama y Asela Reig estudian la partícula ahora sí que en el español de México, mientras que Abelardo San Martín, Cristian Rojas y Silvana Guerrero analizan los marcadores por ser y onda en el habla de Santiago de Chile.

Entre los temas de investigación representados por trabajos individuales, en este número monográfico, se estudian, desde el punto de vista sociolingüístico, el yeísmo en el español de Valencia (José R. Gómez Molina y $\mathrm{M}^{\mathrm{a}}$ Begoña Gómez Devís), la expresión del sujeto pronominal en Granada (Antonio Manjón-Cabeza Cruz, Francisca Pose Furest y Francisco José Sánchez García), la alternancia entre seseo y ceceo en la ciudad de Sevilla (Juana Santana) y la selección modal entre subjuntivo e indicativo en Medellín (Renee Elizabeth Koenig).

Expresamos nuestro agradecimiento a todos los autores que han querido participar en el número monográfico "Estudios sobre la lengua española hablada en el mundo hispánico en su variedad geográfica y social con materiales del PRESEEA" del Boletín de Filología. Asimismo, quisiéramos testimoniar nuestro reconocimiento al profesor Francisco Moreno Fernández y a la profesora Carmen Silva-Corvalán por la iniciativa de poner en marcha un estudio sociolingüístico coordinado del español. Al profesor Francisco Moreno Fernández, Coordinador general del proyecto, también le debemos la nota del epílogo de este número monográfico. Finalmente, agradecemos a la profesora Ana María Cestero, Secretaria ejecutiva del proyecto, por darnos todas las facilidades para la difusión de esta convocatoria, así como a los miembros del Comité editorial del Boletín de Filología por abrirnos este espacio para socializar los estudios contrastivos y descriptivos de algunas de las variedades del español realizados en el marco de los materiales del PRESEEA. 


\section{REFERENCIAS BIBLIOGRÁFICAS}

Lope Blanch, Juan M. 1986. El estudio del español hablado culto. Historia de un proyecto. México: UNAM.

Moreno Fernández, Francisco. 1997. Metodología del "Proyecto para el Estudio Sociolingüístico del Español de España y de América". Trabajos de sociolingüística hispánica. Alcalá de Henares: Universidad de Alcalá, pp. 137-166.

2009. El estudio coordinado de las hablas hispánicas. En María Victoria CamachoTaboada, José Javier Rodríguez Toro y Juana de Jesús Santana Marrero (eds.). Estudios de lengua española: descripción, variación y uso. Homenaje a Humberto López Morales. Madrid: Iberoamericana/ Vervuert, pp. 547-566.

Silva-Corvalán, Carmen. 1994. Direcciones en los estudios sociolingüísticos de la lengua española. Actas del Congreso de la Lengua española. Sevilla 1992. Madrid: Instituto Cervantes, pp. 399-415. 